\title{
Assessing Textbook Cost and Course Data for a High-impact Textbook Lending Program
}

\author{
Posie Aagaard and Jan H. Kemp \\ University of Texas at San Antonio, USA
}

\begin{abstract}
Although open education initiatives are gaining traction at many higher education institutions, the promise of open access or free textbooks for all courses is not yet a reality. Meanwhile, the high cost of textbooks remains an obstacle to academic success for many students. Providing equal access to education is central to the mission of academic libraries, and librarians at the University of Texas at San Antonio decided to support student success by offering a selection of textbooks on reserve. Given a modest annual textbook budget, it was important to identify textbooks that would have the greatest impact on student success. Librarians developed an assessment methodology that identifies lower-division, core courses with high enrollments and expensive textbooks, giving additional weight to courses with a high percentage of students who receive grades of D, F, or who drop the class. Focusing on these criteria, among others, enables the library to provide a selection of high-impact textbooks that circulates heavily and assists students in classes with a demonstrated need for academic support.

\section{Introduction}

Achieving high rates of student success, retention, and graduation is an important goal for institutions of higher education, and academic libraries are employing various approaches to demonstrate the positive impact of their collections and services on student success. Institutions at all levels are working to understand and remove barriers to student success, and one challenging area for many students is the financial cost of a college education, including the high cost of textbooks.
\end{abstract}

In 2016, leaders and policy makers in the state of Florida conducted a student survey to determine the impact of high textbook costs on academic success. Florida's 40 public postsecondary institutions used an online survey, the Student Textbook and Course Materials Survey, to gauge the effect of the cost of course materials and textbooks on students' educational decisions and their progress to graduation. Over 22,000 students completed the survey, and the results indicated that the high cost of textbooks had serious, negative consequences for students, limiting access to courses and slowing progress towards graduation.

The findings suggest that the cost of textbooks is negatively impacting student access to required materials ( $66.6 \%$ did not purchase the required textbook) and learning ( $37.6 \%$ earn a poor grade; $19.8 \%$ fail a course). Time to graduation and/or access to courses is also impacted by cost. Students reported that they occasionally or frequently take fewer courses (47.6\%); do not register for a course (45.5\%); drop a course (26.1\%); or withdraw from courses $(20.7 \%)^{1}$

ALA's strategic planning document, American Library Association Strategic Directions, lists Equitable Access to Information and Library Services as a key action area and notes a "critical need for access to library and information resources, services, and technologies by all people," including those who experience "barriers to equal education." 2 Offering access to selected textbooks, especially during a student's first few college semesters, is one way libraries can support first generation, economically disadvantaged, and minority students, helping their institutions to foster inclusivity and supporting equal access to education.

\section{Context}

The University of Texas at San Antonio (UTSA) was established in 1969 and currently enrolls 32,000 students in over 160 degree programs, including 24 doctoral programs. The school has been designated as a Hispanic-Serving Institution and is classified as a Carnegie R2 doctoral university. In fall $2018,55 \%$ of 
students were Hispanic and $63 \%$ of all students identified as minority. Over $40 \%$ were economically disadvantaged (eligible for Pell grants), and $46 \%$ were first generation college students. In addition, $24 \%$ of students attend school part-time, giving an indication of the number of students who work to support themselves and their families while pursuing their educational goals. To UTSA students, the high cost of textbooks matters.

\section{Background}

The library's textbook lending program was initiated prior to 2009 by instructors who placed their personal copies of course textbooks on reserve for student use. The textbooks were heavily used, and after a semester or two of use, many were literally falling apart. Although the library's collection development policy specifically excluded textbooks (with certain exceptions), librarians saw the heavy student demand for textbooks as an opportunity to support student success. They decided to change the collections policy and allocated $\$ 15,000$ to replace worn out items and purchase additional textbooks for a number of lowerdivision classes with high enrollments and expensive textbooks.

Usage of the textbooks grew, and the library responded by increasing the textbook allocation gradually over the next five years, primarily purchasing books for lower-division courses with high enrollments when the textbook cost was over $\$ 100$. Based on course enrollment, the library purchased from one to six copies of each title, usually one copy for every 100 students. This approach enabled the library to focus on supporting freshman and sophomore students-those who are most at risk for dropping out at UTSA-by providing textbooks for the large survey and core classes. By 2017, the textbook allocation had reached \$70,000, and approximately 4,500 textbooks and other course materials were available on reserve.

\section{Figure 1: Growth of the Textbook Program}

\section{Growth of the Program}

Increased textbook allocation based on high circulations

\section{Purchased multiple copies for large classes}

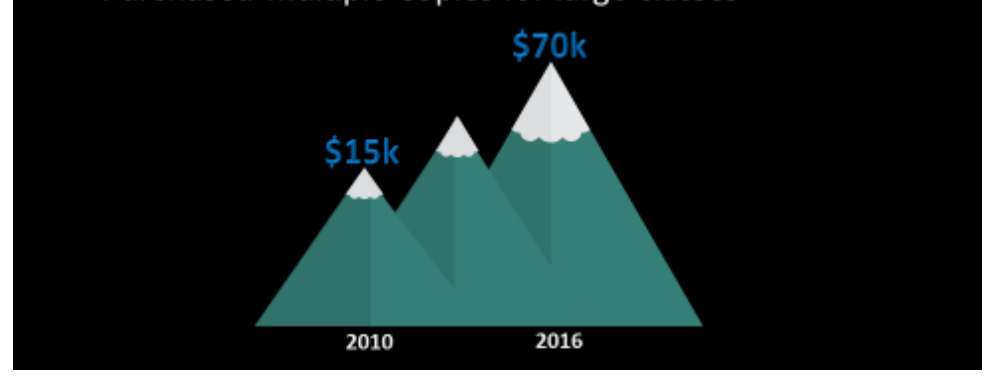

\section{Program Management}

Managing a textbook lending program of this size requires considerable staff time and effort. Textbook titles and editions change frequently, and it is challenging to provide funding for textbooks, given collections budget constraints. Faculty must be notified when textbooks are purchased for their classes so they can inform the students.

Heavy textbook circulation increases the workload at the service desk as well, both in terms of reserves collection maintenance and customer service. For example, when all copies of a textbook are checked out, students' names are placed on a waitlist, and the student is notified when a copy becomes available via a pager system, similar to the pager systems used in restaurants. The library actively promotes the textbook service, with the result that some students expect to find all their textbooks on reserve. Marketing for the textbook service has been changed to emphasize that only selected textbooks are available on reserve. 
Despite the management and service challenges, use of the service has increased, and student feedback provides additional assurance that the value of the service more than justifies the costs. A collateral benefit of textbook lending is that it brings many freshman and sophomore students into the library, allowing us to offer them the wider range of services that support academic success, including laptop lending, group study room reservations, the Writing Center, and more.

\section{Findings}

As mentioned previously, the high-impact textbooks have been heavily used by students. In FY2017, 4,500 textbooks accounted for over $50 \%(84,672)$ of the total physical material initial circulations $(168,725)$.

Comparing the cost per use for textbooks with other materials easily justifies the expenditure of collections funds and staff time, since each textbook receives many more uses than the other print books or DVDs in the collection.

Figure 2: Initial Circulations: Textbooks vs. General Collection* 2014-2017

\section{Initial Circulations: Textbooks vs. General Collection* 2014-2017}

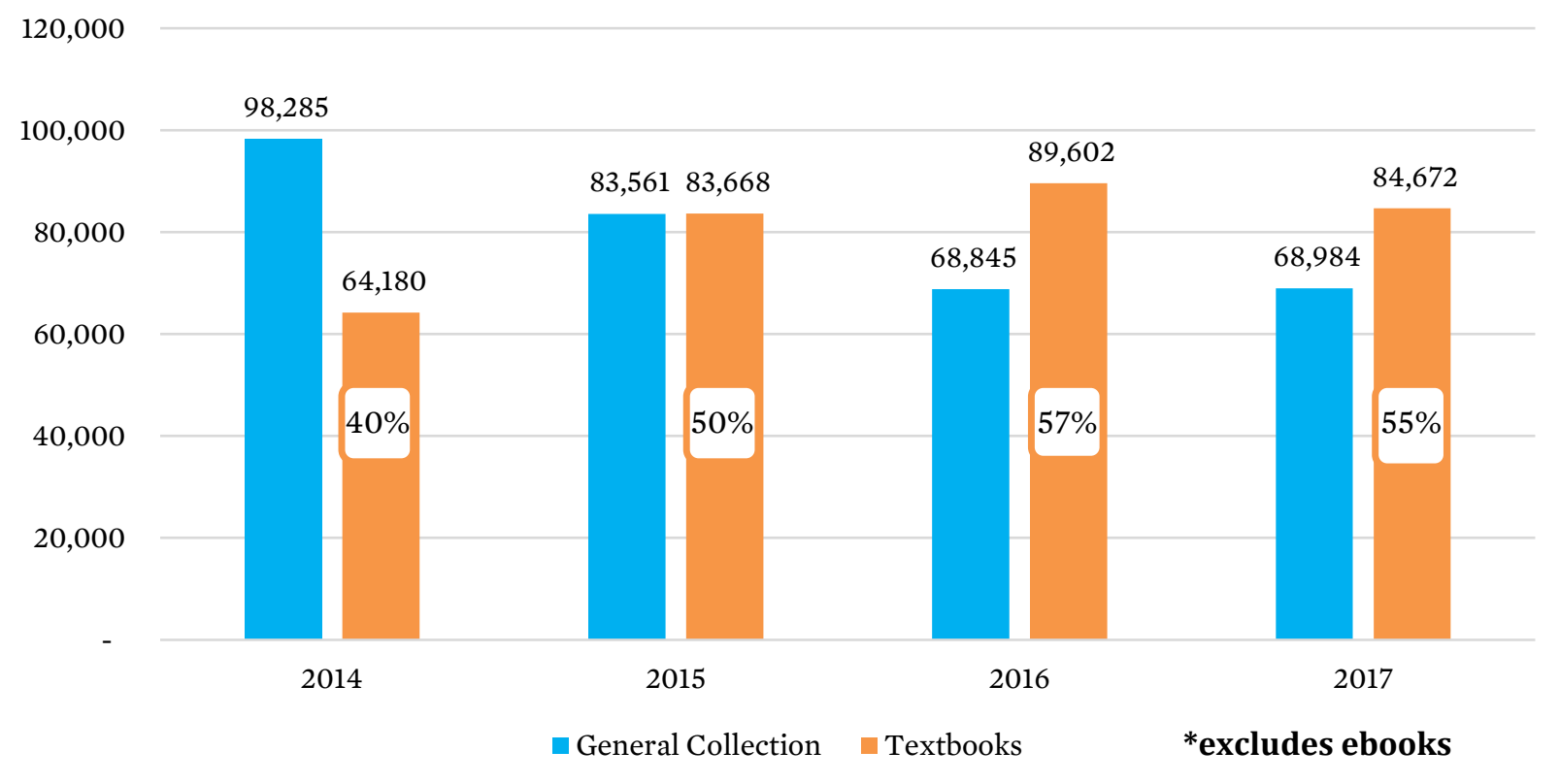

\section{Textbook Strategies}

The print textbook lending program is only one part of the library's textbook strategy, however. Due to the challenges of circulating physical textbooks and in order to better serve users, the library attempts to purchase these materials in electronic format, actively pursuing multiuser e-textbooks as a preferred option. However, relatively few textbooks are currently available in e-formats with student-friendly platforms and multiple simultaneous users, and this option has had a limited impact for high-impact courses. The library also has taken a leadership role on campus in the movement to incorporate low- or no-cost Open Educational Resources or OER materials into courses. The university displays textbook costs in the schedule of classes, so students are aware of the cost of course materials when registering for classes. However, while the library provides grants for faculty who adopt OER materials for their courses, both for individual classes and at the departmental level, only a fraction of classes currently use low- or no-cost textbooks. Therefore, while OER holds much promise, at present it provides only a partial solution at most schools. In the future, the increased availability of textbooks in electronic format and OER together should reduce the demand for print textbooks on reserve. In the meantime, considering that 4,500 textbooks generate half of the library's print initial circulations, this service seems like an excellent value. 
The methodology for identifying and assessing high-impact textbooks has evolved over a period of eight years to include data streams for textbook costs, course enrollment, and course-related student success measures, among others. In the second section, the data collection and assessment methodology and outcomes will be described.

\section{Assessing the High-Impact Textbook Program}

Early analyses of the textbook program were limited to readily available data: raw circulation counts and rough estimates of circulations per textbook. Increased demand for textbooks was evident in the continued upward circulation trend over a multiyear period. Initially, the library did not have an efficient method of identifying textbooks assigned each semester. This caused a variety of related logistical issues, including time-consuming manual course and textbook lookups performed by library staff. The campus bookstore finally succumbed after years of repeated requests and provided the library with access to textbook assignment and cost data by semester.

Analysis of the resulting new data yielded some valuable insights for the library and for the campus. Librarians calculated new averages, including average cost per textbook and average textbook cost by academic department and college. Also calculated was the average number of textbooks assigned by academic department and college, both for undergraduate-level and graduate-level courses. Enrollment data and cost data were combined to calculate cost offset estimates. Textbook circulation data and textbook cost data were combined to produce some rough estimates of cost per circulation. With enrollment data integrated into the analysis, the number of courses and students supported by the textbook program was calculated.

To better understand student demand, the library briefly experimented with a fully demand-driven textbook program alongside the high-impact textbook program. Resulting analyses revealed interesting and concerning patterns-e.g., a disproportionately high number of textbook requests placed by graduate students-that led librarians to refocus the overall textbook program to best support the university's most atrisk students. Rethinking the fundamental questions was crucial: How does the university define the most atrisk students? Is there unmet textbook demand by these students? Which courses have the largest at-risk student populations?

\section{Refining the "High-Impact Course" Designation Methodology}

Previously unseen campus data provided some answers to these questions. When first designing the highimpact textbook program, the library had access to a list of only selected courses with a grade of D, F, or withdrawn (W). Librarians asked the Office of Institutional Effectiveness to provide complete course, section, and instructor data, along with student enrollment counts and aggregated D/F/W data for all courses. The new data provided both a more holistic and a more granular view of enrollment distributions by course, department, and college. The data also revealed the university's recently introduced practice of designating courses critical for student retention as "Success Marker" courses. Identifiers for "Gateway" and "Core" courses-those for which completion is required for students to advance in a degree program or college-were added to this dataset.

To effectively incorporate $\mathrm{D} / \mathrm{F} / \mathrm{W}$ and course enrollment data into the methodology for identifying highimpact courses, it was first necessary to define what constitutes a "high" level of impact. Native data distributions guided the methodology, as the enrollment data combined with $\mathrm{D} / \mathrm{F} / \mathrm{W}$ rates and $\mathrm{D} / \mathrm{F} / \mathrm{W}$ percentages fell neatly into distinct tiers that have remained fairly consistent over time. Notable variances have served as an early indicator of significant enrollment shifts, signifying a change in the curriculum or in department- or college-level degree requirements.

Textbook cost data from the campus bookstore was incorporated into the list of high-impact course candidates to identify the most expensive textbooks in target classes. Analysis of high-impact textbook circulation data was added to identify a purchasing threshold for the number of copies to purchase, based on 
enrollment. As suspected, enrollment and D/F/W data confirmed that courses designated as Success Marker, Gateway, and Core should be folded into the high-impact textbook purchasing program.

Figure 3: The library's Tier One and Tier Two High-Impact Course Criteria

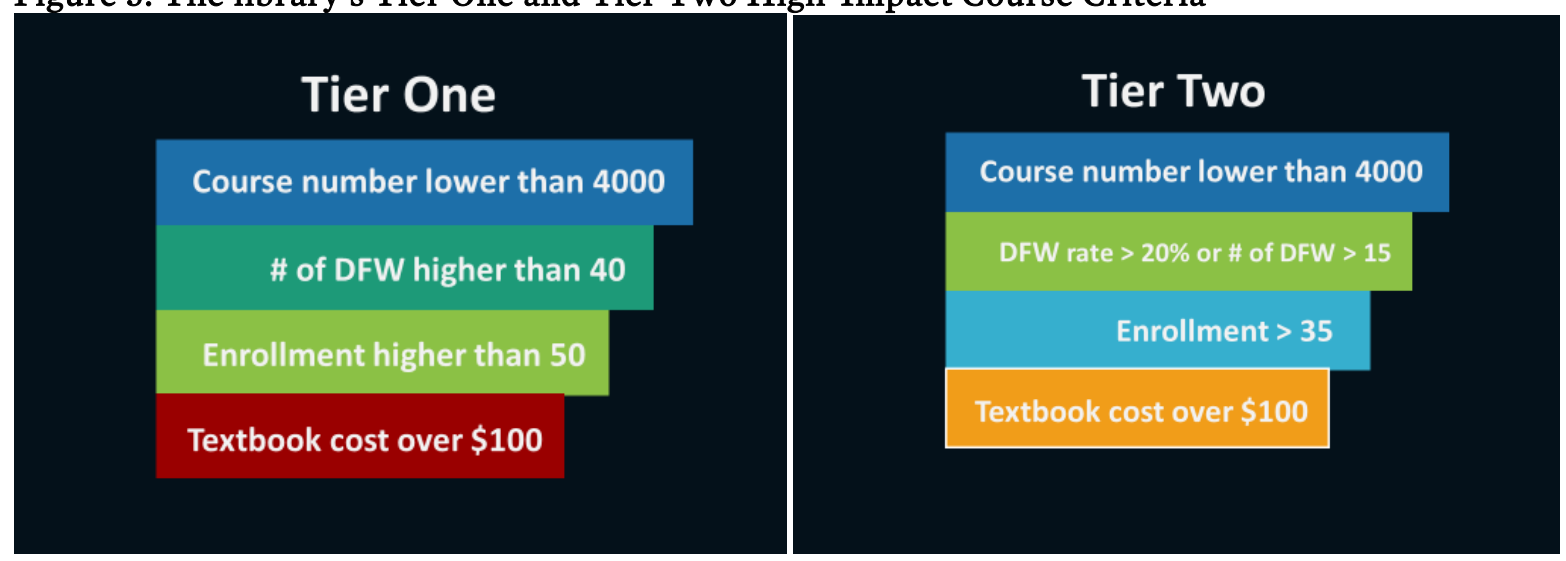

At UTSA, high enrollment and significant D/F/W rates are priority criteria for OER course grants. Much of the analysis for the high-impact textbook program is equally suitable for identifying potential "high-impact" OER course candidates. Courses that have adopted OER materials can easily be tracked, and the corresponding absence of those courses' print textbook circulation statistics can be seen in the textbook circulation data. These OER-influenced declines are desirable print circulation impacts.

\section{Additional Program Refinements}

After observing persistent pockets of unmet user demand not represented in the refined high-impact textbook methodology, the library now incorporates high pager use data into the textbook program analysis and routinely purchases additional textbook copies as a result. Additionally, library staff identify repeatedly requested textbooks that the library does not own, reach out to the faculty who teach the associated courses, and often place a copy on reserve. Textbooks for these courses may not fully fit the definition of highest impact, but this is a cost-effective way to meet users' observed demand through the library's traditional course reserves program.

To stretch funds, the library proactively identifies heavily used textbooks and formats suitable for reinforced bindings. The bindery service is inexpensive, and the books with reinforced binding have remained in remarkably good condition, resulting in savings of thousands of dollars that might otherwise have been spent on replacement copies.

\section{Print Textbook Analysis}

Even with clean metadata, a few potential factors may impact cost per circulation analyses: the cost, the demand, and the availability of an item. Items with a high cost and high circulation or with a low cost and low circulation might reasonably have a low cost per use. High-cost, low-circulation items and low-cost, low-circulation items will have a relatively higher cost per use. Statistics for items with high demand may be artificially low if there is insufficient textbook availability. Identifying which factors drive the results of an analysis can be a helpful exercise. The distribution of each factor across a dataset may also reveal useful information to inform a purchasing strategy.

\section{E-Textbook Analysis}

E-textbook cost per use can be challenging to calculate accurately at scale without a system to ingest e-book usage statistics across platforms and account for possible permutations in print ISBNs and e-ISBNs. For institutions that support hybrid OER-for instance, those who track library-assigned materials as part of the OER effort-e-textbook cost per use can be an informative metric for individually assessed resources. 
E-textbook cost offset can also be a valuable metric. Because of difficulty approximating the cost of etextbooks for individuals compared to the institutional rate, librarians chose an equivalent print-pertextbook cost and multiplied this amount by the number of students enrolled in a course to calculate ballpark e-textbook cost offset figures. A relatively small number of e-textbooks tend to be available for designated high-impact courses, but the library does purchase e-textbooks when available in an access model appropriate for course use.

\section{Potential Pitfalls and Other Considerations}

In the library's high-impact textbook analyses, metadata is king. Cryptic abbreviations, ambiguous and common titles, custom editions with ISBNs that confound reliable identification, multiple versions of similar texts, and missing format information are common in the textbook title and cost data file from the campus bookstore. Authors' names are rarely disambiguated. Prices can vary, depending on whether a textbook is available for purchase or rental, or depending on the format and bundling options.

In addition, textbook editions can change over time. Different editions of the same textbook may be assigned for different sections of the same course. Some textbooks may be assigned to multiple courses and sections, resulting in a many-to-many relationship. Textbook assignments can change from semester to semester or year to year. Not all UTSA faculty report their assigned textbooks to the campus bookstore, which means that analyses built on textbook bibliographic and cost data from that list can be incomplete and potentially inaccurate.

In a multi-copy program, different copies of textbooks may be purchased at different times of the semester. It may be advisable to roll up the collective circulation and cost data for multiple copies over a specific time period, especially for "cost-per" calculations. Similarly, recently acquired, damaged, or lost items should be isolated and possibly removed from "cost-per" calculations. Some data are more sensitive to outliers, potentially skewing averages. For example, in some analyses, zero-cost and zero-usage data for courses with no textbook assigned were removed.

The library had to reconsider integrating faculty-owned textbooks into various textbook program analyses. These textbooks often represent only one of several copies that circulate. Analyzed separately, information about faculty-owned textbooks may lack context. The library now uses the same record and checkout conventions for faculty-owned textbooks as other multi-copy textbooks in the library's collections.

Other helpful tips for analysis: Be mindful when comparing metrics for samples of significantly different sizes. If needed, compare population proportions prior to performing an analysis. When building one analysis atop another, consider how choices made in a base analysis might affect other analyses layered atop the initial analysis. When comparing buckets of data, variations in frequency for the same metric can impact an analysis. For example, textbook circulation periods can be far shorter than circulation periods of general collection items. It is important to account for this variance when reviewing and comparing overall collection circulation counts.

\section{Other Benefits of Analysis}

The library has realized other positive results of the new high-impact textbook methodology and refined program. Information about designated Success Marker, Gateway, and Core courses raised librarians' awareness of the university's evolving curricular strategies, allowing closer alignment with campus priorities. Formalizing the high-impact textbook methodology provided a platform for additional discussions with faculty members and enhanced relationships with existing faculty users of the library's course reserves services. Facilitating access to textbooks through the high-impact textbook program and the OER program reinforces the library's role as supporter of student success.

\section{Conclusion}

At UTSA, the textbook lending program has evolved from merely lending faculty copies of textbooks to the current methodology, a mashup of campus data and textbook information that takes into account student 
performance in a course. Although implementing a textbook lending program requires staff time and effort, the service can be implemented at any level, and the barrier to entry is fairly low. By simply identifying high enrollment classes with expensive textbooks and securing a modest fund allocation, libraries can offer support to lower-division students who may be in need. Including additional sources of data will enable a library to fine-tune the selection process and potentially increase the impact on student success.

As the availability of OER materials and e-textbooks grows, it is likely that the demand for textbooks on reserve will decline. At present, however, the change appears to be an incremental rather than a transformational process. During the transition, high-impact textbook selection strategies can help relieve the high cost of textbooks for students most at risk, supporting student success and equal access to education.

-Copyright 2019 Posie Aagaard and Jan H. Kemp

\section{References}

1. Robin L. Donaldson and E. Shen, 2016 Student Textbook and Course Materials Survey: Results and Findings (Tallahassee, FL: Florida Virtual Campus, 2016), 5, https://dlss.flvc.org/documents/210036/361552 /2016+Student+Textbook+Survey.pdf.

2. American Library Association, American Library Association Strategic Directions (Chicago: ALA, 2015), 2, http://www.ala.org/aboutala/sites/ala.org.aboutala/files/content/governance/StrategicPlan/Strategic\%2 oDirections\%202017_Update.pdf. 